\title{
UNA CULTURA SUFRAGÁNEA: LÉXICO, LENGUAJES Y SABERES DE LA DEPENDENCIA POLÍTICA Y JURISDICCIONAL AL SURESTE DE LA AUDIENCIA DE CHARCAS (SANTA FE, SIGLOS XVI-XVIII)*
}

\author{
A SUFFRAGAN CULTURE: LEXICON, LANGUAGES AND KNOWLEDGE OF \\ POLITICAL AND JURISDICTIONAL DEPENDENCE IN THE SOUTHEAST OF \\ THE AUDIENCIA DE CHARCAS (SANTA FE, 16TH-18TH CENTURIES)
}

\author{
Darío Gabriel Barriera**
}

\begin{abstract}
A partir de textos elaborados desde una perspectiva de pedidos o de reclamos por el cabildo de la ciudad de Santa Fe del Río de la Plata, una ciudad subordinada a la gobernación y el obispado de Buenos Aires y judicialmente a la Real Audiencia de Charcas, el estudio propone examinar la naturaleza de los lenguajes y la configuración de argumentos en esos pedidos para destacar los elementos que, incómoda y convenientemente, fueron de manera recurrente utilizados por el cuerpo político para obtener beneficios o exenciones de sus cabeceras. El autor propone ubicar estos lenguajes dentro de una gramática católica (donde la alegación de pobreza es fundamental) pero a la vez caracterizarlos como propios de una cultura sufragánea, esto es, una cultura política desarrollada por cuerpos políticos dependientes, con el propósito de entablar conexiones con otros casos que compartan esa misma condición.

Palabras claves: Cabildo, cultura política, gobernación, negociación, lenguajes.
\end{abstract}

Based on texts elaborated in the form of petitions or claims by the cabildo of the city of Santa Fe del Río de la Plata, a subordinated city to the Government and Bishopric of Buenos Aires and the Real Audiencia de Charcas, the study proposes to examine the nature of the languages and the configuration of arguments in these petitions in order to highlight the elements that, uncomfortably and conveniently, were recurrently used by the political body to obtain benefits or exemptions from their heads of state. The author proposes to locate these languages within a Catholic grammar (in which the allegation of poverty is fundamental) but at the same time to characterize them as belonging to a Cultura sufragánea, that is, a political culture developed by dependent political bodies, connecting with other cases that share the same condition.

Key words: Cabildo, political culture, governorate, negociation, languages.

Con absoluta modestia, un homenaje a la memoria de António Manuel Hespanha

\section{Introducción}

\section{Para comprender una cultura extraña,} antropología

En un libro cuya traducción al español acaba de cumplir treinta años y que, por muchos motivos, es magnífico, António Manuel Hespanha (1989) nos dejó claves preciosas para comprender el gobierno de las unidades políticas del antiguo régimen católico. Continuando huellas trazadas por los trabajos pioneros de Ernst Kantorowicz y Aaron Gurevich, y en evidente diálogo con su colega coetáneo Bartolomé
Clavero $^{1}$, en Vísperas del Leviatán, Hespanha puso en acto una mirada hermenéutica para reconstruir una antropología política de aquella sociedad, es decir, de "...las representaciones profundas que los hombres tienen de sí mismos y de sus relaciones en sociedad" (Hespanha 1989: 231).

Su apelación a las literaturas jurídica y teológica se apoyaba en que las mismas no encerraban solamente una experiencia literaria, sino que recogían "...los resultados de experiencias sociales de organización". Un autor concreto de un texto jurídico, por ejemplo, podía considerarse “...poco más que el demiurgo de un gran autor colectivo, constituido por la tradición textual...", tradición que más allá de las particularidades, reúne un conjunto

\footnotetext{
* Este artículo ha sido elaborado en el marco de una colaboración como Investigador Asociado para el Centro de Estudios Históricos de la Universidad Bernardo O'Higgins, Chile.

** ISHIR (Investigaciones Sociohistóricas Regionales), Universidad Nacional de Rosario, CONICET (Consejo Nacional de Investigaciones Científicas y Técnicas), Rosario, Argentina; Centro de Estudios Históricos, Universidad Bernardo O’ Higgins. Santiago, Chile. Correo electrónico: dgbarriera@conicet.gov.ar
} 
de rasgos que signan la cultura jurídica europea de la época. Esta consiste en "...una comunidad fundamental de condiciones sociales de vida, por lo menos, una comunidad de modelos sociales de pensar el hombre, la sociedad y el poder"'.

Para Hespanha, la matriz del poder político europeo anterior al siglo XVIII respondía bien a la imagen de "... una constelación de polos relativamente autónomos, cuya unidad era mantenida, más en el plano simbólico que en el efectivo, por la referencia a una 'cabeza' única" que se asemejaba bien al ejemplo más visible y accesible a los legos de "...la dispersión y autonomía relativa de las funciones vitales del propio cuerpo humano..." 3 . Desde su perspectiva, entonces, lo que trasmitían la literatura jurídica y teológica no era tanto una representación o un reflejo de la organización social, sino un relato de la forma en que el poder político estaba organizado en esa sociedad.

Lo que Hespanha rescata y enseña en esas páginas es que según esa literatura, que fue doctrina pero también descripción, en aquel orden los diferentes órganos de la sociedad eran dependientes entre sí. $\mathrm{Y}$ esto tiene consecuencias decisivas en la manera de comprender un universo político radicalmente diferente del nuestro, basado en los conceptos de individuo, libertad y legalidad ${ }^{4}$. Una de las consecuencias derivadas de dicho posicionamiento, que el maestro portugués subrayaba cada vez que tenía ocasión, es que para aquellos hombres y aquellas mujeres, la sola posibilidad de pensar un gobierno político absolutamente centralizado era imaginar algo "...tan monstruoso como un cuerpo que se redujese a la cabeza...” (Hespanha 1989:235).

"El gobierno debería, por lo tanto, ser mediato; debería reposar en la autonomía político-jurídica (iurisdictio) $)^{5}$ de los cuerpos sociales y respetar su articulación natural (cohaerentia, ordo, dispositio, naturae) -entre la cabeza y la mano debe existir el hombro y el brazo, entre el soberano y los oficiales ejecutivos deben existir instancias intermedias-. La función de cabeza (caput) no es, pues, la de destruir la autonomía de cada cuerpo social (partium corporis operatio propria), sino la de, por un lado, representar externamente la unidad del cuerpo y, por otro, mantener la armonía entre todos sus miembros atribuyendo a cada uno aquello que le es propio, garantizando a cada cual su estatuto ('fuero', 'derecho', 'privilegio'); en una palabra, haciendo justicia (conmutativa). Y así es que la realización de la justicia -finalidad que los juristas y politólogos medievales consideran con el primero e incluso el único fin del poder político- acaba por confundirse con el mantenimiento del orden social y político establecido"6 (Hespanha 1989:235-236).

En esta idea en donde las partes (cada órgano) tienen su función en el todo (el cuerpo), cada parte debe ser pensada también como un cuerpo (partium corporis operatio propria) precisamente porque cumple una función (officium). Y por ese motivo, para poder cumplir su función, es que los cuerpos de aquella sociedad necesitaban de autonomía, una “... autonomía funcional de los cuerpos..." ligada al autogobierno

“...que el pensamiento jurídico medieval llamó iurisdictio y en la cual englobó el poder de hacer leyes y estatutos (potestas lex ac statuta condendi), de dar poder a magistrados (potestas magistratus constituendi) y, de un modo más general, de juzgar los conflictos (potestas ius dicendi) y de emitir órdenes (potestas praeceptiva)" (Hespanha 1989:236).

Por todo esto, las formas colectivas o grupales de organización social -ciudades y villas, corporaciones, comunidades religiosas, etc.- encontraban en el derecho la legitimación de cierto "carácter originario" $-\mathrm{O}$ natural $-{ }^{7}$ de sus poderes políticos y de su autonomía, de resultas que la actividad de cualquier poder superior se consideraba “...orientada hacia la resolución de un conflicto entre esferas de intereses, conflicto que el poder resuelve 'haciendo justicia' o sea, atribuyendo a cada uno lo que le compete (suum cuique tribuere)" (Hespanha 1989:237) ${ }^{8}$.

Teniendo presente estas líneas maestras, propongo pensar la relación entre una ciudad sufragánea de la gobernación del Río de la Plata (Santa Fe) y sus cabeceras (Buenos Aires y La Plata -donde residía la Real Audiencia de Charcas-) como un escenario para observar parte de las técnicas o artes de gobierno que desarrollaron estos cuerpos -que Montesquieu llamó intermedios- mediante gestos y lenguajes específicos que se corresponden tanto 
con el modo tradicional de legitimar y gestionar el poder político como con los intereses de las élites de ciudades sujetas a varias jurisdicciones superiores que, para perdurar, debían ejercer el arte de ser parte del cuerpo sabiendo negociar con sus cabezas más cercanas.

\section{Gobernar y ser gobernado}

Santa Fe, fundada en 1573, era la ciudad más antigua de la gobernación del Río de la Plata. Apenas redactada el acta fundacional su fundador le asignó jurisdicción sobre una extensión enorme, de cincuenta leguas a los cuatro vientos, la que desde entonces y hasta que aparecieron reclamos de terceros -es decir, jurisdiccionales-, se consideró su territorio, esto es, la hipótesis de un soporte físico ( $\sin$ demarcar) hasta donde alcanzaba la capacidad de los jueces de la ciudad para decir derecho.

Sin embargo, ni su antigüedad ni su pretenciosa extensión fueron suficientes para convertirla en cabeza de nada. Fue fundada en 1573 dependiente de la gobernación del Paraguay con sede en Asunción. Hasta 1593 su cabildo fue presidido por un teniente de adelantado-gobernador; entre 1593 y hasta 1617 , por un teniente de gobernador dependiente de Asunción, de la que distaba unas 150 leguas por tierra. Cuando en diciembre de ese año el rey dividió en dos la provincia gigante del Paraguay, Santa Fe fue puesta bajo la jurisdicción de la nueva gobernación cuya cabecera se estableció en Buenos Aires, de la que distaba algo menos de 100 leguas. La creación del virreinato en 1776 y la erección de dos Audiencias en Buenos Aires (la primera activa entre 1661 y 1671 y la segunda entre 1785 y su supresión en 1812), no cambiaron su suerte, ya que durante esos períodos la dependencia se movía de La Plata ${ }^{9}$ a Buenos Aires. Tampoco fue sede principal en materia de organización eclesiástica. Los párrocos de su iglesia matriz, así como los del resto de las parroquias de su jurisdicción, dependieron del obispado de Asunción primero y del obispado de Buenos Aires después. En definitiva, Santa Fe fue un pequeño cuerpo dentro del gran cuerpo de la monarquía hispánica, y hasta los años posteriores a la ruptura del vínculo con la metrópoli y la manifestación de su autonomía en 1815 (que el directorio de Buenos Aires no aceptó tranquilamente) su condición fue siempre la de una ciudad sufragánea.
Estos datos nos informan de una situación jurisdiccional que fue regular y constante a lo largo de casi dos siglos y medio -algo que desde luego Santa Fe comparte con muchas ciudades de todas las provincias de la monarquía- que me permito utilizar para conceptualizar la cultura política que se gestó en esa experiencia como ciudad sufragá$n e a$. En materia de gobierno, la historia política de Santa Fe es la de una ciudad que, mientras estuvo contenida dentro la institución política denominada Monarquía hispánica, tramó todas sus relaciones con instituciones próximas (americanas) en materia secular y eclesiástica, siempre desde el lugar de la dependencia. Nunca ocupó la máxima jerarquía en ninguna de las configuraciones institucionales, siempre dependió de cabeceras inmediatamente superiores que se ubicaban entre ella misma y la corte o el rey y, en cualquier caso, ejerció una tenue función metropolitana o intermedia solo sobre sus campañas.

Mi propósito es mostrar de qué manera y por medio de qué figuras e instrumentos esa situación permanente de subordinación a autoridades superiores -cercanas o distantes- promovió (o exigió) de los agentes concretos que se ocuparon del gobierno de la ciudad la elaboración de un lenguaje y de unas posturas que acabaron por forjar una cultura del diálogo y la negociación política que difiere de las que se observan en las ciudades sede de autoridades seculares o eclesiásticas, cuya cultura podría caracterizarse como "relativamente metropolitana".

\section{Para un gobierno mediato}

Las ciudades americanas de la monarquía hispánica tuvieron figuras específicas para actuar en su representación ante autoridades superiores -desde el gobernador hasta el mismo rey, que era el cenit de ese universo político, la cabeza del cuerpo, pasando desde luego por el Consejo de Indias-. La figura del procurador era clave en aquel esquema de poder político que, como señalaba Hespanha, se basaba en el gobierno mediato. Existía como solicitador y representante a distancia en Castilla y en Aragón desde el siglo XIII y no se limitó solo a las ciudades como cuerpo: las aljamas judías también tuvieron los suyos en la Península ibérica.

Una primera distinción puede hacerse entre los que eran numerarios (o del número, esto es, con nombramiento y pago ${ }^{10}$ y los de negocios o causas (afectados a una comisión específica, en 
algunas ocasiones llamados diputados de la ciudad, podían serlo también de varias o procuradores de la gobernación ${ }^{11}$. También existían procuradores de distintos niveles (generales, provinciales, de las Indias..., o como fray Pedro Pacheco, "general de la redención de los cautivos cristianos") que funcionaban como bisagras que recibían peticiones desde adentro y solicitaban hacia afuera dentro de la Iglesia Católica, como los de catedrales o los de la orden jesuítica ${ }^{12}$. Los había además para partes específicas del cuerpo político consideradas particularmente necesitadas de su función - de indios (Puente Luna, 2018), de pobres, que también lo fueron de esclavos (González Undurraga, 2012) - ${ }^{13}$.

Volvamos a los procuradores generales (o síndicos) de las ciudades: los cabildos hispanoamericanos podían elegirlos y destituirlos, pero el nombramiento era firmado por el gobernador y no eran considerados capitulares. Podían incluso accionar contra el cabildo, porque además de representar a la ciudad como cuerpo, también tenían representación de los vecinos. Lo mismo podían exigir a los vecinos el cumplimiento de ordenanzas municipales. A pesar de numerosos pedidos, concesiones, intentos y amagues, esos procuradores no tuvieron presencia en cortes, como algunos pretendían ${ }^{14}$.

\section{La construcción no planificada de un manual de estilos para saber pedir}

En la composición del primer cabildo de 1575, la ciudad de Santa Fe ya había designado procurador y su función consistió en pedir, pero hacia adentro. Antonio Martín solicitó a los vecinos que "aya peso y medida para que vivamos en razón” y a estas cuestiones de interiores y de conservación de la ciudad -por ejemplo impedir que se fueran algunos vecinos que querían moverse- estuvieron abocadas las primeras intervenciones ${ }^{15}$. El primer registro de mediación entre la ciudad y una autoridad superior que presento tiene que ver con una autoridad eclesiástica: el 22 de octubre de 1584, el cabildo pidió al procurador que solicitara al vicario eclesiástico una solución (claro está, religiosa) a la invasión de langostas que destruían los "mantenimientos" de la ciudad ${ }^{16}$ mientras que, al año siguiente, se le solicitó que interviniera ante el obispo para que no entraran en vigor las nuevas constituciones, "muy perjudiciales" para la ciudad ${ }^{17}$.

La ausencia de un procurador era considerada un asunto serio y su reemplazo se trataba con urgencia.
Esto ocurrió en 1590, cuando se desconocía el paradero de Juan Jaques (quien se había ido "furtivamente" de la ciudad, "sin papeles de la ciudad" "sin saber a dónde va"). En la elección de su reemplazo se advierte de todos modos un sentido práctico, ya que se escoge a Juan Ramírez (a la sazón alguacil mayor) con el propósito de que compareciera ante la Real Audiencia de Charcas porque viajaba de su cuenta a la ciudad de La Plata ${ }^{18}$.

En 1592 el cuerpo extendió un poder al procurador Diego de Olabarrieta para pedir mejoras ante "su magestad el muy poderoso señor presidente y oidores de la ciudad de la Plata y ante su excelencia del señor Visorrey, y ante quien el Cabildo deba y pedir las ordenanzas...". Lo curioso de este pedido es que Olabarrieta, a quien se encomendaba accionar ante quien el Cabildo deba, era vecino de Asunción -no de Santa $\mathrm{Fe}$-. Además, léase que la aprobación de las "cosas apeladas de este Cabildo" eran solicitadas por el procurador ante el metropolitano -adjetivo que se utiliza en el texto para reemplazar todo lo que concierne a las sedes superiores ${ }^{19}$-.

En febrero de 1594, el cabildo instruyó al procurador Feliciano Rodríguez para solicitar ante el gobernador Fernando de Zárate (en Asunción) la confirmación de los términos y jurisdicción de la ciudad, licencia para vaquear en la jurisdicción de Buenos Aires -por la ayuda que Santa Fe le había prestado en su fundación y población, debido al anegamiento de las tierras de vaquería en Santa $\mathrm{Fe}-\mathrm{y}$ respeto por los fueros del cabildo. También que visitara personalmente la ciudad "porque tiene necesidad dello" 20 .

En 1621, aunque Pedro Ramírez había sido electo procurador de la ciudad, instituyó al capitán Hernando de Rivera Mondragón para que presentara algunas solicitudes puntuales frente a la nueva máxima autoridad provincial -el gobernador de Buenos Aires-. El emisario debía pedir a Diego de Góngora la concesión de licencias para hacer corambre y sebo de toros. Además de alegar que existía un exceso de toros cimarrones, el argumento fuerte radicaba en que el permiso serviría para aliviar el estado de pobreza de la ciudad, agravado en esta ocasión por la escasez de las “....cosechas que se han tenido de pan y vino"21. Como ocurriría en muchas ocasiones, una de las razones por las que Herrera Mondragón fue comisionado por los capitulares era porque el hombre viajaba a Buenos Aires de su cuenta y cargo. Este aprovechamiento del traslado físico de un vecino a ciudades donde tenían sede 
autoridades superiores (Asunción, Buenos Aires, La Plata en Charcas) se volvió un hábito que permite comprender algunas colaboraciones (como el pedido a un vecino de Asunción que viajaba a Charcas) tanto como la íntima conexión entre el cuerpo local y sus integrantes - los vecinos $-^{22}$.

Esta relación íntima entre las partes y el todo podían desatar discusiones en cuestiones como el honor: cuando el regidor Fernández Montiel pidió que la ciudad revocara el poder otorgado a Domingo de Leyva para representarla ante la Real Audiencia de Charcas, su defensor -el alcalde Juan López de Vargas- destacó que en él concurrían dos virtudes intachables: era hijo de conquistador -por tanto, persona benemérita- y solventaba los gastos del viaje porque había tenido en cuenta la pobreza de la ciudad. Fernández Montiel, para cuestionarlo, arremetió contra las dos bases: aseguró que, siendo muchacho, lo conoció haciendo oficios de zapatero (algo indigno para un vecino) y dijo que ignoraba que hiciera viajes al Perú para comerciar haciendas (sugiriendo su insolvencia) ${ }^{23}$.

La cuestión del procurador solventando el viaje, como se ve, era importante. Pero no siempre había que viajar a pedir: otras veces, la fuente iba al cántaro. Cuando el gobernador de Buenos Aires pasaba por la ciudad, el escenario del pedido se invertía, y era la ciudad misma. En septiembre de 1621 el gobernador Diego de Góngora, de paso por la ciudad camino de la de Corrientes, hacia el norte, asistió a la reunión de alcaldes y regidores para comentar su viaje pero también para escuchar los pedidos que quisieran presentarle. En el toma $y$ daca de toda relación entre gobernante y gobernados que negocian, Góngora pidió el acatamiento de cuatro autos y dos reales cédulas, una de estas -la del 10 de octubre de 1618- ordenaba copiar en el libro del cabildo y pregonar la confirmación de las ordenanzas de Alfaro $^{24}$. Los capitulares no dejaron pasar la oportunidad para reseñar el estado de pobreza de la ciudad, “...la ruina de sus edificios y la falta de mantenimientos..." disponiendo que el procurador gestionara todas las medidas convenientes para conservarlos y aumentarlos. Pero el punto más tenso de la negociación fue cuando el gobernador solicitó una escolta de 50 hombres de la ciudad para su viaje a Corrientes y Concepción del Bermejo: la respuesta (negativa) no se argumentó desde luego en la falta de razones del solicitante sino en una trayectoria histórica de las relaciones entre las ciudades involucradas. Los capitulares aseguraron que Corrientes y Concepción habían tenido actitudes insolidarias respecto de Santa Fe. De modo que, a la negativa de la escolta, agregaron un pedido al gobernador: que esas ciudades quedaran bajo su jurisdicción para, en un futuro, poder exigirles mutualidad en la defensa pese a la gran distancia que las separaba ${ }^{25}$.

En 1651, cuando el gobernador de Buenos Aires (Jacinto de Lariz) convocó a los vecinos de Santa Fe para confirmar la tenencia de sus encomiendas, el cabildo también reaccionó corporativamente. Con el argumento de que la más importante de las encomiendas existentes "no pasa de 20 tributarios" y presumiendo (con razón) que esas concesiones iban a ser retiradas, el cabildo pidió por medio de su procurador que no se innovara en la materia, ya que la medida “....aumentaría la suma pobreza de los pobladores" 26 . El cuerpo pide a la cabeza de la gobernación la conservación de una situación anterior para evitar que la pobreza de los vecinos aumentara.

\section{La necesidad tiene cara de hereje}

La fortuna de este refrán en español no tiene que ver con su contenido, que era bien otro. Fue una cuestión de simpatía sonora la que travistió en esos términos una fórmula romana que decía algo diferente: necessitas caret legge, esto es, la necesidad carece de ley. Ese principio buscaba argumentar el perdón mediante un motivo fuerte -la exención de la vigencia de la ley- para quien hubiera cometido un delito o hubiera hecho algo distinto a lo que la ley mandaba en una situación desesperante. En una sociedad corporativa, no obstante, el principio fue esgrimido sobre todo por las corporaciones o los diferentes cuerpos que componían la monarquía. Por este mismo motivo, el horizonte que parece orientar la construcción de una imagen de la ciudad como pobre, en general sin recursos, floja de energías, poco potente, y en alguna ocasión, desesperada ${ }^{27}$, deriva en un mecanismo retórico para justificar-algunas veces-el incumplimiento de mandatos superiores. Ese no era su destino único ni principal.

Ya en 1594, el argumento para solicitar una reducción en los aranceles fijados por el provisor y vicario general Rodrigo Ortiz Melgarejo - pidiendo que se volviera a los establecidos el año anterior por el arcediano del Paraguay y Río de la Plata, Martín del Barco Centenera-fue la pobreza de la ciudad ${ }^{28}$. 
Más tarde, en el contexto del fallecimiento de Felipe III y de la asunción de Felipe IV, el cabildo recibió la orden de realizar exequias para el rey muerto y las honras de rigor para el rey puesto. Una vez más, la ciudad respondió con un retrato colectivo y corporativo de su pobreza. La cabeza del gobierno debía asumir que no todas las ceremonias y galas que se mandaban (algunas de ellas costosas) serían posibles. Como en el refrán, la ciudad esperaba ser eximida de cumplir por desesperación. Pero también aprovechaba la comunicación para hacer un pedido al gobernador: la concesión de una licencia para vaquear en el Valle Calchaquí "y 20 indios para los trabajos", cuyo producido se utilizaría para reparar la iglesia matriz. En esta ocasión, el pedido fue a las dos cabezas de gobierno: el obispo recibió otra nota donde se enunciaban las necesidades del edificio de la iglesia mayor de la ciudad, deteriorado por una pobreza que, a estas horas y gracias a la pertinaz secuencia de sus propios relatos, la ciudad podía caracterizar como inveterada ${ }^{29}$.

La coyuntura del traslado de la ciudad a su nuevo sitio (Santa Fe fue trasegada 12 leguas al sur entre 1651 y 1661) fue crítica y las excepciones solicitadas se potenciaron, planteando pedidos que involucraban hasta cuestiones mínimas, como la gestión de materiales para funcionar como cabildo. En febrero de 1651 la ciudad solicitó al virrey del Perú permiso para usar papel común en lugar del rubricado "...teniendo en cuenta la pobreza de la tierra y el traslado de la ciudad" 30 . En enero de 1671, ya en el nuevo sitio, la solicitud a la gobernación tiene que ver con la escasez de hombres para cubrir los cargos del cabildo: a falta de regidores propietarios, se pide elegir seis regidores ${ }^{31}$ para cubrir las ausencias de los vecinos que-ocupados en sus faenas o nombrados para comisiones en otras ciudades- habían dejado el capítulo reducido a sus dos alcaldes ordinarios ${ }^{32}$.

La década de 1710 fue muy intensa para la ciudad de Santa Fe del Río de la Plata. Los pueblos nativos del sur chaqueño habían sumado gente y ganado fuerza. Mocovíes y abipones, llamados genéricamente "guaycurúes", recuperaban terreno $\mathrm{y}$, desde el norte y el oeste, saqueaban chacras y atacaban las puertas de la ciudad que los europeos habían introducido como su principal dispositivo de invasión, conquista y colonización del territorio. Durante esa década y la siguiente, todos los que conformaron el elenco gobernante de la ciudad consideraron la posibilidad de un segundo traslado -el primero había sido entre 1650 y 1660, cuando abandonaron la vera del río San Javier para trasegarla a la del Salado, doce leguas al sur-.

En estas circunstancias críticas, el cabildo enviaba urgentes y angustiadas solicitudes al gobernador de Buenos Aires: a comienzos de 1710, le solicitó que por su extrema pobreza le disminuyera el precio de las armas que necesitaba comprar (a la gobernación) para hacer una entrada contra los pueblos que nombraban como "infieles", "indígenas" y "enemigos", a veces alternativa y otras conjuntamente. Como el gobernador no accedió a tal rebaja, el cabildo -después de discutirlo- pidió que le prestasen el armamento, por hallarse la ciudad exhausta de medios y sus vecinos en bastante pobreza $a^{33}$.

La situación de la ciudad -ora pobre en sî misma, ora pobre por la pobreza de sus vecinos-era expuesta regular y detalladamente, fuera porque sus principales miembros no encontraban el modo de hacer negocios más o menos redituables o porque algunos, de espíritu menos paciente o compelidos a tomar decisiones más drásticas, directamente la abandonaban y se marchaban a probar suerte en otros destinos. La pintura, en líneas generales, precedía no solo el pedido de una rebaja en el precio de unas armas o su desesperado préstamo: pasaba lo mismo con los "subidos impuestos", la postergación de construcciones civiles o militares, la suspensión de expediciones militares, el abandono de algún fuerte estratégico o hasta la modificación de costumbres que ya eran tradición en la ciudad -como la de acompañar el real estandarte a pie en lugar de a caballo, o la de suspender las populares corridas de toros que se celebraban para la fiesta de San Jerónimo, el patrón de la ciudad- ${ }^{34}$.

Lo cierto es que el tópico de la pobreza precedía indefectiblemente alguna solicitud a la instancia superior de gobierno: debido a que eran tan pocos y tan pobres, argumentaba el cabildo en septiembre de 1713 , pidió repatriar a los santafesinos que andaban por Corrientes y Buenos Aires ${ }^{35}$. Un par de años más adelante, expuesto "el lamentable estado en que se halla la ciudad", se propuso al gobernador la suspensión de la sisa, al mismo tiempo que se le pidieron armas, municiones, y hasta la designación de un vecino en el cargo de teniente de gobernador: Francisco de Ziburu "... por sus cualidades y general aceptación"36.

Aquello de que contra el vicio de pedir está la virtud de no dar lo tenía muy incorporado la 
ciudad como agente político. De los escritos que sus escribanos prepararon durante años para el gobernador de Buenos Aires se desprende no solamente contenidos, sino también una obsesión de forma: en ellos, la ciudad era mentada en tercera persona y los pedidos del cambiante elenco de vecinos que la gobernaba se expresaban como imperiosas necesidades que vivía el cuerpo político en virtud del bien común ${ }^{37}$.

\section{Un horizonte de expectativas}

De cualquier modo, aunque la pobreza de la ciudad era asumida como extrema, nunca fue presentada como insoluble. De esto también dependía el éxito en el arte de pedir. Por ese mismo motivo, los capitulares podían poner en palabras las cuestiones que se relacionaban con su condición de ciudad sufragánea y de punto de paso entre los nodos más importantes del sur del virreinato peruano.

Esta condición de lugar intermedio es la que movió a la ciudad a solicitar se instalara -como en Córdoba- una aduana ${ }^{38}$. En abril de 1624, con motivo de instruir al ilustre Hernando Arias de Saavedra como procurador ante el oidor charqueño Alonso Pérez de Salazar -a cargo del gobierno del Río de La Plata- los vecinos le solicitaron que permitiese la entrada de plata acuñada a Santa Fe, "por hallarse muy pobre la ciudad y sus vecinos". La falta de metálico es un clásico de la historia de las ciudades sufragáneas en el Río de la Plata durante los siglos XVI y XVII, pero en los años 1620, esta carencia se agravaba por la falta de lienzo, sayal y hierro, monedas de la ciudad desde sus primeros días. El más atrevido de los pedidos era, no obstante, que los gobernadores y tenientes de gobernadores no se entrometiesen en "dar licencia para vaquear en el Valle de Calchaquî", y solicitaban que ese asunto quedara solo bajo la gestión capitular "por ser los animales de esa zona propiedad de los vecinos de Santa Fe" 39 .

El pedido de las licencias no se debía a que el ganado fuera caro o escaso -al contrario, el valor por "cabeza" que podía negociarse como derechos de vaquear era tan bajo que llevó al cuerpo a ponerle un piso- sino a cuestiones relacionadas con la apreciación que del mismo hacía esa comunidad (Grenier, 1996) y, sobre todo, a la defensa de su autonomía política respecto de la cabecera. En 1625 el cabildo decretó que la cabeza vacuna fuera "moneda de la ciudad". Para dar fuerza al papel en cuestión -con total claridad acerca de la situación de dependencia- el decreto fue elevado para su confirmación por la Real Audiencia de las Charcas. Junto con el pedido, el procurador -en esta ocasión, Pedro de Mendieta- fue instruido nuevamente para gestionar la instalación de una aduana en la ciudad, también "por su pobreza" 40 .

En 1654, el argumento de la pobreza de Santa Fe y de sus vecinos se esgrime para solicitar la suspensión del traslado de la ciudad si no se logra$b a$ una autorización para vaquear en la otra banda del Paraná (actual provincia de Entre Ríos). Aquí la petición involucraba a terceros particulares y viejos conocidos de las familias capitulares: los derechos sobre esas vaquerías estaban en posesión de los descendientes de Jerónimo Luis de Cabrera. Don Francisco Luis de Cabrera -además, nieto de doña Jerónima de Contreras y de Juan de Garay, el fundador de la ciudad- fue invitado al cabido y el cuerpo le sonsacó una donación de 20.000 cabezas para aplicar a los gastos del trasiego ${ }^{41}$. Lo interesante es que la ciudad solicitaba a un particular con argumentos idénticos a los que utilizaba para hacerlo ante la gobernación.

También se pedían otros beneficios y derechos para mejorar "los propios" (recursos de la ciudad). En 1686, el cabildo otorgó poderes a Juan de Berazategui y Alonso Martínez Montes para solicitar al rey la concesión del derecho de romana -que hasta entonces gozaba la orden franciscana para la construcción de su convento-; que cediera a la ciudad por cuatro años el derecho de alcabala y que le enviara armas y pólvora. El pedido al rey, arguye el cuerpo, se debe a que los socorros son recibidos continuamente por las ciudades cabecera de las provincias de Buenos Aires y Tucumán, y no llegan a las ciudades sufragáneas ${ }^{42}$, planteando de esta manera una desigualdad en la distribución de los recursos regios.

Una de las procuraciones más sonadas en este sentido fue la que el Cabildo encargó a Juan José de Lacoizqueta el 12 de mayo de 1738, nombrándolo apoderado ante el Consejo de Indias -también aprovechando un inminente viaje suyo a España- con el objeto de gestionar para la ciudad el privilegio de Puerto Preciso ${ }^{43}$. Aunque este viaje no se concretó $^{44}$, ante otro inminente viaje de Lacoizqueta, esta vez a la ciudad de La Plata, sede de la Real Audiencia de Charcas, el cabildo le extendió otro poder para representarlo ante esta otra cabeza -que podía dictar provisiones en nombre del rey- para 
"implorar su socorro". Los fondos a los que daría lugar ese privilegio, decía la ciudad, se utilizarían para financiar los gastos de la guerra "contra los infieles" y trataba de corregir los efectos nocivos de la reciente creación de los arbitrios sobre yerba, tabaco, azúcar, algodón, carretas y vino, los que desalentaban a los mercaderes a realizar operaciones en la ciudad ${ }^{45}$.

\section{Reflexiones finales}

Cuando la ciudad pedía a las autoridades superiores, lo hacía por escrito y casi siempre mediante un procurador designado como numerario o de manera eventual, aprovechando un movimiento individual a favor del cuerpo. Generalmente el cabildo redactaba las instrucciones para su procurador que, entonces, debía conocer tanto las técnicas de la negociación oral de la comunicación escrita, dominada por unos pocos.

Como en los casos que ya analizamos de comunicaciones entre campesinos y la gobernación (Barriera 2018), los pedidos de una ciudad sufragánea pueden analizarse también como peticiones o solicitudes que, si bien no provienen de la base-del piso-, sí surgen desde un intermedio que, colocado en función de pedir, minimiza su valía para mejor provocar el efecto que, supone, garantiza el éxito de la gestión.

La forma de estas solicitudes obligaba a las ciudades y a sus procuradores a reiterarse. En esas repeticiones y en su persistencia -donde se deja adivinar quizás una expectativa positiva acerca de la eficacia de la fórmula- se jugaba con la comunicación a las autoridades superiores (los metropolitanos) una imagen de debilidad, de inferioridad o una incapacidad como preludio a un pedido. Este podía ir desde la suspensión de una obligación a la reducción de ciertas cargas, pasando por la solicitud de una merced o un beneficio. ${ }^{46} \mathrm{La}$ dinámica comenzó con la vida de la ciudad como cuerpo político, y fue puesto en práctica por hombres (varones) que, aunque provenían de Asunción del Paraguay, no disponían de gran experiencia ni de un manual de prácticas para hacerlo.

Uno de los argumentos más reiterados en el marco de distintos tipos de articulaciones respecto de la situación principal, cual es la de la dependencia política y jurisdiccional, fue la condición de pobreza extrema. Una extensa literatura demuestra que, para la cultura que los europeos exportaron como moderna, la pobreza no era precisamente un estado envidiable ${ }^{47}$. Muy por el contrario, la masiva salida de hombres embarcados a Indias $a$ valer más vinculaba con la búsqueda de una mejora económica, de un ascenso social y se tomaban altos riesgos porque la crisis agraria, ambiental y política europea era de proporciones sistémicas, como la que había vivido en el año 1000 (Flinn 1989). Ya hemos visto además, que si un vecino había sido pobre o trabajado en un oficio manual, algunos podían pensar que no era digno de representar a la ciudad como su procurador, porque la contaminaba con su mácula. Por otra parte, en la cultura europea medieval, la pobreza se asociaba con la fealdad y la vergüenza (Mollat 1988). ¿Qué tan bueno, entonces, podía ser esto de esgrimir pobreza para obtener concesiones desde la cabeza?

La pregunta no es inocente, y me permite introducir la sospecha de que, detrás del aparente uso estratégico y racional para tener éxito en sus pedidos por recursos o por eximición de obligaciones, la permanente inclusión de la pobreza en las peticiones no se verificaba con comodidad. Quiero decir que para los capitulares santafesinos -que desde el siglo XVII y durante el XVIII en muchos casos eran ricos- no debió ser agradable referirse a la ciudad como un cuerpo pobre, incluso si esto era conveniente. Si revisamos las primeras sesiones del cabildo, a finales del siglo XVI, cuando el propio cuerpo designó a dos de sus miembros para inspeccionar las tasaciones de oficios, les ordenó que los trabajos mal hechos fueran quemados o entregados a los pobres -en ese orden- ${ }^{48}$. Esto quiere decir que quizás debamos tratar de comprender la elaboración de este lenguaje en la incomodidad. Algo que puede permitirnos comprenderlo es que los capitulares eran padres de la patria y, por tanto, su gobierno era doméstico. Argumentaban y buscaban recursos como gobernadores de una casa ${ }^{49}$. En este sentido volvemos a encontrar las claves de lectura política que proponía A. M. Hespanha, ya que

"Los conceptos que en este discurso determinaban la existencia de una comunidad política (persona ficta, universitas) expresaban la unidad esencial que vinculaba a sus miembros y la consecuente personificación de la misma. Por su parte, la noción orgánica (corpus) permitía esquematizar la composición interna de la comunidad según un orden 'natural' de jerarquías 
que distinguía a los diversos componentes en función de su misión dentro del todo, fijando, a la vez, sus diferencias cualitativas y el carácter necesario e irreductible de cada uno" (Lorente y Vallejo 2012:102).

En consecuencia, el léxico y los lenguajes elaborados en torno al pedido de beneficios o exenciones, desarrollando el arte de ser ciudad sufragánea y no cabeza -en el caso de Santa Fe, durante dos siglos y medio-, aludían a la pobreza porque esa condición formaba parte de la gramática católica de la desesperación pero también de la esperanza, porque de la superioridad se esperaba generosidad y gracia. Y los que tenían derecho a esperarla eran, en primer lugar, los más débiles, los pobres.

Estos lenguajes, por tanto, no eran estrategias fingidas ni emergieron -como a veces se presenta en trabajos que analizan estos pedidos aisladamente- de una crisis puntual. En cualquier caso, lo que afloraba fluidamente en coyunturas críticas -como la del traslado, la de la década de 1720 o las de 1780 con la supresión del puerto preciso- era una retórica que no se había tomado de un manual de estilo sino forjado en común saber hacer de estos vecinos que, como domésticos gobernadores de la casa, utilizaron mecanismos y dispositivos aprendidos por transmisión y mejorados por la práctica.

En las formaciones políticas antiguorregimentales, lo normal era el gobierno mediato, con articuladores que se ocupaban no solo de conectar con la cabeza sino también con otras cabezas que eran a un tiempo otros cuerpos intermedios ${ }^{50}$, invitándonos a leer la comunicación política repensando los clásicos esqumeas top/down y bottom/up, típicos del centralismo. Por este mismo motivo no es posible encontrar una reflexión teórica abstracta sobre el particular, por eso aparecen las incomodidades (como el doble filo de la utilización de la pobreza como principal argumento) o las contradicciones (vecinos ricos que pueden pagarse largos viajes, ciudades pobres, que deben aprovecharlos): los lenguajes y actitudes combinadas en las negociaciones entre una ciudad sufragánea y las diferentes cabezas de las que depende van definiendo saberes que componen una cultura política que solamente podía germinar en esa posición, esto es, en sedes de poder político que siempre dependieron de otras cabeceras-gobernación, virreinato, intendencia o Real Audiencia-. En ellas, las relaciones de dependencia aparecen naturalizadas -como parte de un orden que hasta comienzos del siglo XIX no fue concretamente subvertido-. Pero en la negociación con las instancias superiores se generan elementos diferenciales a los que aparecen en las ciudades que tuvieron una experiencia de civis caput-como en el espacio charqueño es el caso, en diferentes grados, de Buenos Aires, Córdoba, La Plata, Asunción o Montevideo-. Estudié la ciudad de Santa Fe, e invito a pulsar esta hipótesis en otras ciudades sufragáneas.

El vocablo elegido para adjetivar la particular configuración de estos lenguajes y saberes es muy corriente en el vocabulario de la Iglesia Católica, donde diócesis sufragánea es aquel obispado dependiente de una sede metropolitana o provincial, a cargo de un obispo que, por estar a cargo de la misma, es denominado arzobispo. Sin embargo, en su primera acepción, el adjetivo sufragáneo califica a aquello que depende jurisdiccionalmente, de manera lata, y no es exclusivo de lo eclesiástico. Por otra parte, el adjetivo diocesano (tan asociado con el gobierno de la Iglesia) proviene del vocabulario político de la Grecia antigua, ya que en esa lengua diócesis significaba administración, gobierno o provincia ${ }^{51}$. Por último, la división tajante entre gobierno laico y eclesiástico quizás debe más a nuestras proyecciones del pasado que a las realidades de un gobierno sin más que, en la monarquía católica, encontraba por otra parte sus fundamentos jurídicos en donaciones papales y convenciones que fueron cuestionadas por otros interesados en la medida en que el gobierno del mundo se convirtió en objeto de disputa por otras potencias ${ }^{52}$. A guisa de ejemplo, ya hemos visto cómo era el cabildo -y no el párroco- el que gestionaba ante el obispado los fondos para arrelgar el edificio de la iglesia matriz.

El peso del uso de la pobreza en el lenguaje político respecto del que trata este artículo no era desde luego exclusivo de este tipo de ciudades (otras culturas de la solicitud se ventilaban también en las cortes o en las peticiones de las personas) ni operaba en el vacío: formaba parte -y esto deberá establecerse por medio de comparaciones- de un énfasis particular a la hora de negociar la obediencia en la monarquía católica ${ }^{53}$. Si pudiéramos ampliar observaciones locales de lo que los agentes cultivan como habitus en nombre de un cuerpo político, quizás podamos saber más acerca de las artes de la negociación en las culturas políticas antiguorregimentales y coloniales.

Un último párrafo de quienes fueron los nexos entre la ciudad sufragánea y sus cabeceras, los 
procuradores. Hay muchos estudios pertinentes a la figura en particular y a ellos he remitido. Son un clásico ejemplo de go-between, passeur o broker. Solamente me gustaría añadir que en este verdadero gobierno de archipiélagos que fue la monarquía hispánica, ellos fueron las naves que conectaron sus islotes, manteniendo la comunicación entre sedes más o menos cercanas o muy lejanas. Finalmente, su presencia física y su capacidad (económica, biológica y cultural) de desplazarse para hacerse presente donde la ciudad no podía o ante quienes no venían a la ciudad, morigeraba eficazmente los efectos de la distancia geométrica y, en definitiva, hacía posible el gobierno a pesar de las grandes distancias (Guillaume Gaudin, 2017).

\section{Referencias Citadas}

Agamben, G.

2014 Altísima pobreza. Adriana Hidalgo, Buenos Aires.

Bailyn, Bernard y Denault, Patricia L. (ed).

2009 Sounding in Atlantic history. Latent structures and intellectual currents, 1500-1830. Cambridge, Massachusetts, London, England; Harvard University Press.

Bahena Pérez, M. A.

2020 "Negociar la ciudad. Procuradores de la gobernación de Guatemala en el Consejo de Indias, 1531-1540”, Nuevo Mundo Mundos Nuevos [En ligne], Débats, mis en ligne le 24 février 2020, consulté le 04 mars 2020. DOI : https:// doi.org/10.4000/nuevomundo.79357

Barriera, D. G.

2002 "Por el camino de la historia política. Hacia una historia política configuracional”. Secuencia. 53:163-196.

Barriera, D. G.

2017 Abrir puertas a la tierra. Microanálisis de la construcción de un espacio político. Santa Fe, 1573-1640. 2da Edición. Ministerio de Innovación y Cultura, Santa Fe [1 $1^{\mathrm{a}}$ ed. 2013].

Barriera, D. G.

2018 "Gouverner les campagnes. Analyse micro-sociale et construction institutionnelle. (Río de la Plata, fin du xviiie siècle)". Annales. Histoire, Sciences Sociales. 73-1:57-82.

Bautista y Lugo, G.

2018 "Sirviendo en la paz y en la guerra con mucha fidelidad. Trayectorias de mediación en los mundo sibéricos, 15541656". Mediterránea, 44, 427-454. DOI 10.19229

Bayle, C.

1952 Los Cabildos Seculares en la América Española. Sapientia S. A. de Ediciones, Madrid.

Bonnet, D.

1992 Los protectores de naturales de la Audiencia de Quito. Siglos XVII-XVIII, FLACSO, Quito.

Brangier, $\mathrm{V}$.

2019 Saber hacery decir en justicia. Culturas jurídico-judiciales en la zona centro-sur de Chile (1824-1875). Prohistoria Ediciones, Rosario.

Castro Olañeta, I.

2013 "Vuestra magestad se sirva de ordenar al governador que no pariete en las ordenanzas del visitador. Gobierno colonial y poder local en la Gobernación del Tucumán (1603-1619)". Bibliographica americana. Núm. 9.

Clavero, B.

1981 "Historia y Antropología. De la división convencional de las ciencias sociales". Llull. 4:21-33.

Clavero, B.

1991 Antidora. Antropologia catolica de la economia moderna (Per la storia pensiero giuridico moderno). Giuffré, Milano.
Clavero, B.

1992 Institución Histórica del Derecho. Marcial Pons, Madrid.

Cunill, C. y Quijano, F.

2020 "Los procuradores de las Indias en el Imperio hispánico: reflexiones en torno a procesos de mediación, negociación y representación". Nuevo Mundo Mundos Nuevos [En ligne], Débats, mis en ligne le 24 février 2020, consulté le 04 mars 2020. URL : http://journals.openedition.org/ nuevomundo/79934

Damianovich, A.

1991 "Juan José de Lacoizqueta: Gestor del privilegio santafesino de Puerto Preciso". América, vol. 10.

Dueñas, A.

2010 Indians and Mestizos in the "Lettered City" Reshaping Justice, Social Hierarchy, and Political Culture in Colonial Peru. University Press of Colorado. Boulder.

Cunill, C. y Quijano, F.

2020 "Los procuradores de las Indias en el Imperio hispánico: reflexiones en torno a procesos de mediación, negociación y representación”. Nuevo Mundo Mundos Nuevos [En ligne], mis en ligne le 24 février 2020, consulté le 04 mars 2020. URL : http://journals.openedition.org/nuevomundo/79934 Grenier, J-Y.

1996 L'Economie d'Ancien Régime : Un monde de l'échange et de l'incertitude. Albin Michel, París.

Hespanha, A. M.

1989 Vísperas de Leviatán. Instituciones y poder político (Portugal, siglo XVII), Taurus, Madrid [1987 en portugués; trad. de Fernando Bouza Álvarez].

Forconi, M. C.

2019 "Defensa, comercio y redes políticas. Santa Fe durante las primeras reformas borbónicas". Anuario IEHS, 34 (2).

Flinn, M. W.

1989 El sistema demográfico europeo. Crítica, Barcelona.

Gaudin, G. et al.

2017 "Vencer la distancia: Actores y prácticas del gobierno de los imperios español y portugués". Nuevo Mundo Mundos Nuevos [En ligne], Débats, mis en ligne le 02 octobre 2017, consulté le 08 janvier 2021. DOI : https://doi.org/10.4000/ nuevomundo.71453

González Undurraga, C.

2012 "El abogado y el procurador de pobres: la representación de esclavos y esclavas a fines de la Colonia y principios de la República". SudHistoria, 5.

Lorente, M. y Vallejo, J. -coordinadores-.

2012 Manual de Historia del Derecho. Tirant Lo Blanch, Valencia. 
Lorenzana de la Puente, F.

2010 La representación política en el Antiguo Régimen. Las Cortes de Castilla, 1655-1834. Tesis. Universidad de Extremadura. Cáceres.

Mazin, $\mathrm{O}$.

2016 Una ventana al mundo hispánico. Ensayo bibliográfico I, con la participación de Carmen Saucedo. El Colegio de México, México.

Mazin, O.

2017 Gestores de la Real Justicia. Procuradores y agentes de las catedrales hispanas nuevas en la corte de Madrid. II. El ciclo de las Indias (1632-1666). El Colegio de México, México.

Mollat, Michel

1988 Pobres, humildes y miserables en la Edad Media. Estudio social. FCE. México.

Monlau, P. F.

1858 Diccionario etimológico de la lengua castellana. Madrid.

Moriconi, $\mathrm{M}$.

2011 Política, piedad y jurisdicción. Cultura jurisdiccional en la Monarquía hispánica. Liébana en los siglos XVI-XVIII. Prohistoria Ediciones, Rosario.
Puente Luna, J. C.

2018 Andean cosmopolitans: seeking justice and reward at the Spanish royal court. University of Texas Press. Austin.

Rebagliati, L.

2017 “'Un honorífico empleo’. Apuntes para el estudio de los defensores de pobres en el Río de la Plata (siglos XVIII-XIX)". Revista da Faculdade de Direito UFPR, v. 62 , n. 3, p. 157-186, set./dez. 2017. Acesso em: 21 dez. 2017. DOI: http://dx.doi.org/10.5380/rfdufpr. v62i3.52965.

Tarragó, G.

2012 "The long kiss of goodbye: Santa Fe and the conflict over the privilege of Puerto Preciso (1726-1743)". G. De Luca \& G. Sabatini. Growing in the Shadow of an Empire. How Spanish Colonialism Aflected Economic Development in Europe and in the World (XVI th-XVIII th cc.). Franco Angeli, Milano.

Zamora, R.

2017 Casa poblada y buen gobierno. Oeconomía católica y servicio personal en San Miguel de Tucumán, siglo XVIII. Prometeo Libros, Buenos Aires.

\section{Notas}

1 Abordé estas propuestas hace veinte años durante la preparación de mi tesis doctoral. Volqué sus implicancias sobre el análisis del poder político en Barriera, 2002. La mejor síntesis de lo que esto significa para la historia del antiguo régimen en general se encuentra en la introducción de Moriconi, 2011.

2 Todo en Hespanha, 1989:232, citando a Clavero, 1981. Años más tarde, Clavero propuso un esquema todavía más radical acerca de este aspecto. Sugirió que la distinción esencial entre ius positivum (partes disponibles del derecho, las modificables por los seres humanos) y ius naturale (las partes del derecho que son indisponibles) no la realiza el ius, ni la iurisprudentia ni la lex, sino la teología. Clavero, 1992: 40.

3 Hespanha, 1989:232-233. El pensamiento medieval estaba dominado por la idea de cuerpo, de una “...organización supraindividual, dotada de entidad diferente de la de las partes, que perseguía la consecución de fines propios y autoorganizada o autorregida en función de esos fines". Justamente fue el pensamiento contrarrevolucionario el que revalorizó las concepciones corporativas del medievo. En el periodo de entreguerras existió una historiografía europea que constituyó una “....reacción contra la historia retrospectiva del liberalismo y del constitucionalismo..." propia de la coyuntura europea. Ponía el acento en los fenómenos mentales e ideológicos y fue atacada duramente por el materialismo. Sin embargo, a partir de que la historia ha considerado que los "sistemas políticos" son "autorreferenciales" -que su legitimación es parte del sistema mismo-, aquella historiografía de la "escuela corporativa" ha sido recuperada. Hespanha, 1989, p. 233.

4 La radical alteridad que suponía este mundo condujo a Clavero (1981 y 1991) a plantear incluso la inutilidad de los útiles disciplinares de la Historia para comprenderlo.
5 Cuando se refiere a la ley como iurisdictio Clavero escribe: "La misma legislación se tiene por una forma de iurisdictio, de declaración y no de creación del derecho; no se concibe como una actividad sustancialmente distinta a la judicial". Clavero 1992: 39.

6 A pesar de las nuevas tecnologías de reconocimiento electrónico de rasgos únicos de las personas (huellas dactilares, iris del ojo) todavía hoy, en documentación oficial -documentos de identidad, pasaportes, carnets de conducir, de bibliotecas, etc.- es la imagen de la cabeza la que representa al individuo. Sin embargo, y a pesar de la potencia de esta representación, que sobrevivió varias revoluciones, en el antiguo régimen la representación no es reductibilidad. Para aquella concepción nos recuerda Hespanha (y lo hacía en sus clases) los miembros dispersos de una persona no son la persona, lo que la hace persona es el ensamble: esto permite entender la idea constitutio del cuerpo como un todo, y así, a la idea antigua de constitución.

7 El carácter natural de la jurisdicción de los cuerpos se encuentra notoriamente desarrollado en Baldo.

8 Hespanha afirma en este texto que la matización del concepto de iurisdictio fue lo que llevó a la distinción de niveles y ámbitos de poder y “....permitió conceptualizar el complejo de relaciones políticas de un sistema de poder esencialmente pluralista...", expresado en la riqueza del campo conceptual iurisdictio/imperium. "En su forma acabada [...] la distinción aparece establecida de la siguiente forma. La jurisdicción ordinaria es la que es establecida por la ley o la costumbre, por el príncipe, por el papa o por el rey, y que abarca la generalidad de las causas de una ciudad o provincia. La jurisdicción delegada, por el contrario, es la que solo abarca causas individualizadas y es ejercida en nombre de otro". Hespanha 1989: 238.

9 Donde residía la Real Audiencia de las Charcas, de la que Santa Fe dependió judicialmente entre 1573-1661 y entre 
1672-1785. La distancia era de unas 370 leguas y los viajes podían tener duraciones variables según el objeto. Remito a Barriera 2017.

10 Aunque los hubo también numerarios y ad honorem, como fue el caso de Santa Fe.

11 Bahena Pérez, 2020.

12 Bailyn y Denault, 2009. De los procuradores de los cabildos eclesiásticos existe una extensa bibliografía. Un estudio completo en Mazin, 2017. También Bautista y Lugo, 2018.

13 Las diferencias entre procurador y protector o defensor (de naturales, de pobres o de menores) son no tanto de función como de nombramiento y se verifican en su emplazamiento y representación (a quiénes, ante quiénes), por lo que es preciso ver cada título. Los diccionarios de la época recogen esta cercanía (ver Autoridades, 1731, p. 392) y los vocabularios de los siglos XVII y XVIII en otras lenguas (como el Vittori, 1609, al italiano), aluden a posibles sinonimias entre procurador y protector. En pocos casos coexistieron (como en Lima, Dueñas, 2010). La presencia del primero suponía la cobertura suficiente de las funciones de representación, ya que protectores y defensores generalmente representaron, pleitearon y también procuraron otras gestiones para sus partes. Sin embargo los primeros procuradores de naturales (así designados en América) tuvieron sede solamente en las audiencias y las grandes distancias eran insalvables para los naturales de las ciudades sufragáneas que, justamente, debían acudir a los protectores de naturales locales. En el caso de los procuradores de causas que podían encontrarse en las ciudades, estos solo estaban obligados a una representación que podía ser casuística o temporalmente, por lo que en muchas ciudades se nombraron protectores o defensores costeados por el cabildo o la gobernación. Ahora bien, según Bonnet (1992: 123), "un procurador de causas solo podía participar defendiendo a los indios cuando la parte contraria estaba en manos de un protector o por la inexistencia de este". Sobre los diferentes contenidos, alcances y requisitos asignados y exigidos a protectores y defensores de naturales véase Rebagliatti 2017. Gaudin et al. (2017: 7) han señalado que son pocos los estudios dedicados a "la presencia en la península de representantes de las personas y de las instituciones americanas". Para quien desee un panorma más amplio, remito al reciente dossier acerca de los procuradores publicado por Cunill y Quijano (2020).

14 Bayle 1952:225 y ss.

15 AGSF, AC, Tomo I, pássim.

AGSF, AC, Tomo I, f. 82.

AGSF, AC, Tomo I, f. 94.

AGSF, AC, Tomo I, ff. 117-118.

AGSF, AC, Tomo I, ff. 148-149.

AGSF, AC, Tomo I, ff. 181-182.

AGSF, AC, Tomo I, f. 346.

2 La distancia entre las ciudades americanas y las Cortes de Castilla impidió una presencia masiva en las mismas, aunque algunos autores consideran la participación de sus procuradores no obstante como importante. También se verificaron juntas de procuradores en México y Lima, donde se reunían los representantes de ciudades menores para gestionar por delegación en Madrid. El proyecto de celebrar cortes trienales en América, no prosperó. Mazin 2006.
23 AGSF, AC, Tomo II, ff. 256v-258v., sesión del 4 de febrero de 1626.

24 Sobre las ordenanzas y otros pedidos que suscitó en la misma dirección, Castro Olañeta 2013.

25 AGSF, AC, Tomo I, ff. 356v-359.

26 AGSF, AC, Tomo III, f. 188, sesión del día 1 de febrero de 1651. Énfasis mío.

27 A finales del siglo XVIII, un regidor en funciones de fiel ejecutor, dijo que la gente de la ciudad estaba "desesperada" por la falta de yerba. AGSF, AC, Tomo XV, f. 278.

28 Archivo General de la Provincia de Santa Fe (AGSF), Actas Capitulares (AC), Tomo II, ff. 182-183. De cualquier modo, tampoco el arancel del arcediano había parecido blando a los santafesinos. Barriera, 2017:239.

29 AGSF, AC, Tomo II, ff. 18v-19v., sesión del 21 de marzo de 1622.

30 AGSF, AC, Tomo III, f. 190 v-191.

31 Desde el traslado, el cabildo estaba funcionando con tres regidores propietarios.

32 AGSF, AC, Tomo IV, f. 251.

33 AGSF, AC, Tomo VII, ff. $23 \mathrm{v}-24 \mathrm{v}$.

34 AGSF, AC, Tomo VII, ff. 149v-150v., sesión del 16 de septiembre de 1713. Años después, en 1804, a pocas semanas de las fiestas patronales, el cabildo santafesino resolvió no hacer las corridas de toros para San Jerónimo "por la suma pobreza de esta ciudad". AGSF, AC, Tomo XVII A, f. $180 \mathrm{v}$.

35 AGSF, AC, Tomo VII, f. 151.

36 AGSF, AC, Tomo VII, f. 335, sesión del 12 de julio de 1717.

$37 \quad$ Lo mismo sucedía desde luego con los pueblos de indios y los argumentos que los caciques presentaban para sus tasas o retasas. “...cuando se decidió extinguir el sistema de encomiendas (1718), se exceptuaron aquellas en las que, por la pobreza de sus pueblos, los indios tributaban 'voluntariamente' con su servicio personal (Real Decreto de 1720)". Lorente y Vallejo 2012:249.

38 AGSF, AC, Tomo II, ff. 146-147v.

39 AGSF, AC, Tomo II, ff. 146-147v.

40 AGSF, AC, Tomo II, ff. 205-206, sesión del día 23 de junio de 1625 .

41 AGSF, AC, Tomo III, ff. 348-349, sesión del día 5 de enero de 1654.

42 AGSF, AC, Tomo V, ff. 241-243, sesión del día 18 de noviembre de 1686 .

43 AGSF, AC, Tomo X, ff. 426-427.

44 Alejandro Damianovich (1991) piensa que suspendió este viaje y viajó a Charcas porque tenía sus bienes embargados. Se basa en la petición que su esposa, Doña Juana Márquez Montiel, presentó en nombre de su marido ausente en Charcas 12 de diciembre de 1738 “...para que se le liberara del pago de la contribución obligatoria para la construcción del palacio real de Madrid, en virtud de encontrarse embargados los bienes del matrimonio por la Real Justicia".

45 Respecto de la relación entre frontera, gastos, familias comerciantes y la gestión de este privilegio véase Tarragó 2012 y Forconi 2019.

46 De habilidades frente a la justicia en las personas, aunque para el siglo XIX, Brangier 2019.

47 Debe considerarse como excepcional el modo en que los franciscanos tematizaron el tema que, como ha mostrado 
bien Giorgio Agamben (2014), va más allá de una radical oposición al derecho de propiedad e incluso de su carácter especular respecto de la soberanía.

48 Cabildo de Santa Fe, sesión del 22 de junio de 1576. AGSF, AC, Tomo I, f. 7 v.

49 Sobre el particular véase el libro de Zamora 2017.

50 Esto era, además, conseguir justicia (Hespanha, 1989: 235-236).

51 Eso es siguiendo a Corominas. Monlau (1858:251) para Diócesis consigna: del g. dioikesis, gobierno, administración, d. de dioikeó, gobernar, administrar, d. de oikos, casa, habitación.
52 De todos modos, los conflictos por posesiones coloniales se desataron también entre coronas aliadas en materia religiosa. Con la Paz de Westfalia (1648) y el tratado de Utrech $(1713,1715)$, “...el mapa colonial se fue dibujando a la sombra de tratados inter-europeos basados en un 'derecho de gentes' en el que las comunidades originarias no contaban en absoluto. Veamos algunos de los argumentos desarrollados en este proceso". Lorente y Vallejo 2012:236.

53 Acerca de las ciudades y sus pedidos en las cortes de Castilla, Lorenzana 2010. 